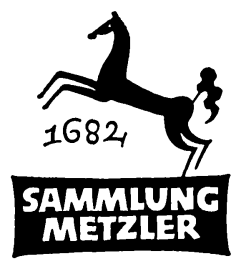

REALIEN ZUR LITERATUR ABT. D:

LITERATURGESCHICHTE 
BURGHART SCHMIDT

\section{Ernst Bloch}

LCM XXXV

J.B. METZLERSCHE VERLAGSBUCHHANDLUNG STUTTGART 
CIP-Kurztitelaufnahme der Deutschen Bibliothek

Schmidt, Burghart:

Ernst Bloch / Burghart Schmidt -

Stuttgart: Metzler, 1985.

(Sammlung Metzler; Abt. D, Literaturgeschichte)

ISBN 978-3-476-10222-5

NE:GT

ISBN 978-3-476-10222-5

ISBN 978-3-476-03926-2 (eBook)

DOI 10.1007/978-3-476-03926-2

M 222

(C) Springer-Verlag GmbH Deutschland 1985

Ursprünglich erschienen bei J. B. Metzlersche Verlagsbuchhandlung und Carl Ernst Poeschel Verlag GmbH in Stuttgart 1985 
I Das Entstehen des Werks im Lebenslauf

1. Philosophie, Lebensalter und das Problem des

Biographischen

2. Blochs Wirken in der DDR nach der Nazi-Zeit ............. 3

3. Beginn von Blochs Philosophieren: Gegensatz Ludwigshafen-Mannheim als Paradigma

4. Das Studium und die Anstöße …………......................... 11

5. Das Frühwerk und die erste Emigration ……................. 16

6. Die zweite Emigration und das Entstehen der Hauptwerke 22

7. Rückkehr nach Deutschland und das späte Werk

II Das Fragen nach dem Augenblick in der Geschichte: destruktiv-konstruktiv

1. Bloch und Lukács über Utopie-Tendenz bei Marx und im Marxismus.

Vorblick in aktueller Diskussionssituation

2. Blochs Grundproblem

3. Blochs Grundproblem erkenntnistheoretisch: Unkonstruierbarkeit des Fragens

4. Blochs Grundproblem metaphysisch: Der Augenblick existentiell als Schlüssel zum "möglichen "Sein

5. Bezug des Augenblicks und des Fragens zur

Geschichtstheorie

a) Geschichtlichkeit des unkonstruierbaren Fragens und des Augenblick-Dunkels. Verhältnis zum Marxismus

b) Wandlungen zwischen Frühwerk und Spätwerk Ernst Blochs

c) "Auszugsgestalt" als Grundkategorie der Geschichte

d) Das Identitätsproblem der Geschichte

e) Das Fortschrittsproblem der Geschichte:

Ungleichzeitigkeit

6. Diskussion des Irrationalen als Konsequenzmöglichkeit des unkonstruierbaren Fragens nach dem

Augenblicks-Dunkel

7. Blochs Weiterungen seines Grundproblems …............... 88

8. Zum Verhältnis von Utopie und Kritik:

Bloch-Diskussion heute

III Schein, Erscheinung, Vor-Schein: Zur figurierenden Teleologie von unten im Naturverhältnis des Menschen

1. Trennung von Natur- und Geisteswissenschaften

2. Blochs Dialektik der Natur 
3. Schein - Erscheinung - Vorschein

4. Das Problem der Gestalt-Theorie: Auszugsgestalt in der Natur

5. Objektivität der Phantasie: Der Naturbezug der vorscheinenden Auszugsgestalt

6. Naturgesetzlichkeit und Auszugsgestalt ....................... 137

IV Bibliographie

A Werke Blochs ........................................................... 141

B Monographien und Sammelbände zu Blochs

Philosophie

C Aufsätze zu Blochs Philosophie

D Werke mit wichtigen Diskussionsbeiträgen zu Blochs

Philosophie

E Weitere verwendete Literatur

V Anhang

Blochs internationale Wirkung, berichtet und mit

Auswahlbibliographien von Francesco Coppellotti (Italien),

Brigitte und Dick Howard (USA), Gérard Raulet

(Frankreich) und Gordana Skorić (Jugoslawien)

Namensregister 
Für Alpha, an Beta erinnernd

Oder: Wer A sagt, muß auch einen Kreis drum schlagen

(A)

Vorliegendes Buch geht großenteils auf die Arbeit für ein Seminar über Ernst Bloch zurück, das der Verfasser zusammen mit Remo Bodei am Aloisianum in Galarate bei Milano gehalten hat. Die Abschnitte 1-4 des Teils II lagen einem Vortrag zugrunde, der im November 1984 am Collège International de Philosophie, Paris diskutiert wurde.

Leider kont zu Teil I nicht mehr Peter Zudeicks ebenfalls werkbiographisch gemeintes Buch "Der Hintern des Teufels « berücksichtigt werden, weil das Manuskript Ende März zum Erscheinungstermin von $\mathrm{Zu}-$ deicks Buch für den Druck abgeschlossen war.

Zur Zitation: Zitiert wird im Text durch Kurzformen, die auf die ausführlichen Angaben zu den Zitatorten in der Bibliographie verweisen. Die Bibliographie ist in die Rubriken A, B, C, D, E untergliedert. Deren Rubrikcharakter findet man angegeben im Inhaltsverzeichnis.

Bele-Ile-En-Mer Sept. 1985 B. S. 